Tropical Journal of Pharmaceutical Research June 2018; 17 (6): 1209-1213

ISSN: $1596-5996$ (print); 1596-9827 (electronic)

(C) Pharmacotherapy Group, Faculty of Pharmacy, University of Benin, Benin City, 300001 Nigeria.

Available online at http://www.tjpr.org

Original Research Article

http://dx.doi.org/10.4314/tjpr.v17i6.30

\title{
Concomitant treatment of brain metastases with whole brain radiotherapy and temozolomide protects neurocognitive function and improve quality of life
}

\author{
Yufei Zhan ${ }^{1}$, Xiaodan Jiang ${ }^{1,2 *}$ \\ ${ }^{1}$ Department of Neurosurgery, Zhujiang Hospital, Southern Medical University, ${ }^{2}$ The National Key Clinic Specialty, The \\ Neurosurgery Institute of Guangdong Province, Guangdong Provincial Key Laboratory on Brain Function Repair and \\ Regeneration, Guangzhou, 510282, China
}

*For correspondence: Email: Jiangxiaodan020@163.com

Sent for review: 20 April 2018

Revised accepted: 28 May 2018

\begin{abstract}
Purpose: To study the protective effects of a combination of temozolomide (TMZ) and whole brain radiotherapy (WBT) on neurocognition, and its effect on the quality of life (QoL) in patients with brain metastasis (BM) from solid tumors, relative to WBT alone.

Methods: A total of 256 BM patients were enrolled and divided into two groups treated with either WBT plus TMZ, or WBRT alone. All patients received 30 Gy WBT, with or without concomitant TMZ (75 $\mathrm{mg} / \mathrm{m}^{2} /$ day) during the irradiation period, and subsequently up to six cycles of $T M Z\left(150 \mathrm{mg} / \mathrm{m}^{2} /\right.$ day).

Results: The mean intracranial objective response (IOR) for all patients was $44.80 \%$ while the IOR for WBT arm and WBT+TMZ group arm were 32.48 and $56.56 \%$, respectively $(p=0.03)$. The median intracranial overall survival (OS) for all the patients was 7.70 months. The median OS for WBT alone group (6.53 months) was significantly shorter than that of the WBT + TMZ arm (9.57 months). Statistically significant difference in quality of life $(\mathrm{QoL})$ was observed between both arms at six months. Moreover, WBT $+T M Z$ group had higher incidence of toxicity, when compared to WBT-only group. Conclusion: These results suggest that co-application of WBT and TMZ improves intracranial ORR and median OS in BM patients, relative to the use of WBT alone. Although the side effects may be increased as a result of addition of TMZ, toxicity is tolerable and manageable.
\end{abstract}

Keywords: Brain metastasis, Temozolomide, Whole brain radiotherapy, Neurocognition

\begin{abstract}
This is an Open Access article that uses a funding model which does not charge readers or their institutions for access and distributed under the terms of the Creative Commons Attribution License (http://creativecommons.org/licenses/by/4.0) and the Budapest Open Access Initiative (http://www.budapestopenaccessinitiative.org/read), which permit unrestricted use, distribution, and reproduction in any medium, provided the original work is properly credited.

Tropical Journal of Pharmaceutical Research is indexed by Science Citation Index (SciSearch), Scopus, International Pharmaceutical Abstract, Chemical Abstracts, Embase, Index Copernicus, EBSCO, African Index Medicus, JournalSeek, Journal Citation Reports/Science Edition, Directory of Open Access Journals (DOAJ), African Journal Online, Bioline International, Open-J-Gate and Pharmacy Abstracts
\end{abstract}

\section{INTRODUCTION}

The prognosis of BM which occurs in approximately 20 to $40 \%$ of adult cancer patients, is usually poor $[1,2]$. Brain metastasis (BM) usually arises from primary malignancies of breast, lung, kidney and gastrointestinal origin [3]. Patients with untreated BM hardly survive beyond one month $[1,4]$. The treatment of $\mathrm{BM}$ involves inputs from several medical disciplines, and entails radiotherapy (whole brain), as well as surgical and systemic therapies [5].

Temozolomide (TMZ) is a new oral alkylating agent. The incorporation of TMZ to whole brain radiotherapy may improve the response rate of 
patients with brain metastases [6-10]. Previous studies have reported that patients suffering from glioblastoma [11,12]; breast cancer $[13,14]$ and lung cancer $[15,16]$ placed on a TMZ and WBT responded much better than patients receiving radiotherapy alone.

The present investigation was aimed at evaluating the effectiveness and safety of combining TMZ with WBT in the management of BM from solid tumors. The survival benefits, neurocognition and QoL of patients on WBT with or without TMZ were also evaluated.

\section{METHODS}

\section{Subjects}

Eligible patients were aged 18 to 80 years whose primary malignancies were confirmed through histology. Brain metastasis was confirmed by gadolinium-improved $\mathrm{MRI}$ or CT scan. The ECOG status of the subjects ranged between 0 and 3 , and their biochemical and hematological profiles were within accepted ranges (leukocytes $\geq 3.5 \times 10^{9} / \mathrm{L}$, platelets $\geq 100 \times 10^{9} / \mathrm{L}$, bilirubin $\leq$ $25 \mu \mathrm{M}$, creatinine $\leq 150 \mu \mathrm{M}$, and creatinine clearance $\geq 60 \mathrm{~mL} / \mathrm{min}$ ). In addition, the enrolled subjects had no uncontrolled morbidities. The exclusion criteria covered subjects given prior medical attention for BM, patients with serious morbidities, as well as pregnant and breastfeeding patients. This research was approved by the Ethical Committee of Southern Medical University ((approval number = S201308-02), and it complied with the guidelines of the Declaration of Helsinki promulgated in 1964 as amended in 1996 [17]. All subjects gave signed informed consent prior to the treatments.

\section{Study design and procedures}

Patients were randomly assigned to receive WBT (127 cases), or WBT plus concomitant TMZ (129 cases). Conformal radiotherapy (parallelopposite and lateral, 2) was given at a total dose of 30 Gy in 15 fractions for three weeks, along with oral TMZ $\left(75 \mathrm{mg} / \mathrm{m}^{2}\right)$, given daily till the end of the radiation period. After a four-week break, patients received up to six cycles of adjuvant TMZ (150 $\mathrm{mg} / \mathrm{m}^{2}$ ) daily for five days every twenty-eight days.

\section{Determination of neurocognitive function and QoL}

Health-related neurocognitive function and quality of life were measured using revised Hopkins Verbal Learning Test (HVLT-R) and subject-completed Functional Assessment of
Cancer Therapy (FACT), respectively. The HVLT-R is a learning and memory test in which the patient is asked to learn and recall a list of twelve words over three trials [18]. The FACTGeneral (FACT-G) version 4 is a twenty-sevenitem package with a five-point Likert scale core multidimensional questionnaire for evaluating various domains of quality of life such as physical, functional, family, social, and emotional domains [19].

\section{Treatment evaluation and definitions}

Baseline assessment was performed weekly before the study. Weekly evaluations of progress response were carried out during concurrent treatment. Evaluation was carried out for four weeks after completion of treatment protocol for the first six months, and then every two months thereafter. It involved laboratory tests, brain CT or MRI and clinical evaluation, with objective response rate (ORR) as primary end-point, while the secondary endpoints involved overall survival (OS), neurocognitive function (NCF), and quality of life (QOL). Complete response (CR) referred to the absence of all traces of BM, while partial response (PR) referred to $50 \%$ or greater reduction in quantifiable brain lesions (BL), or a clear improvement in quantifiable BL. The ORR referred to the percentage of subjects with decreased tumor size of a pre-defined degree within a definite time frame.

\section{Statistical analysis}

The baseline characteristics of the two groups were subjected to statistical analysis using Fisher's exact test or chi-square test, while survival was analyzed with the method of Kaplan-Meier. Log-rank test was used in comparing survival curves. All tests (two-sided) were performed using SPSS 23. Values of $p<$ 0.05 were considered statistically significant.

\section{RESULTS}

\section{Characteristics of enrolled subjects}

A total of 239 patients completed the treatment and were assessed for treatment effectiveness (122 in the WBT + TMZ group, and 117 in the WBT-alone group). The clinical, demographic, pathological and baseline disease characteristics of the patients are listed in Table 1. There were no significant differences between the two treatment groups.

\section{Responses and survival of patients}

A total of 239 patients were assessed for 
responses. The average intracranial ORR for all patients was $44.77 \%(107 / 239)$. Patients who received WBT plus TMZ had an ORR of $56.56 \%$ while WBT alone patients had ORR of $32.48 \%$. The median IOS for all subjects was 7.7 months (95\% Cl $=6.71-8.69$ months). The median OS of the WBRT + TMZ group (9.57 months) was longer than that of the WBRT-alone group (6.53 months, $p=0.001$ ).

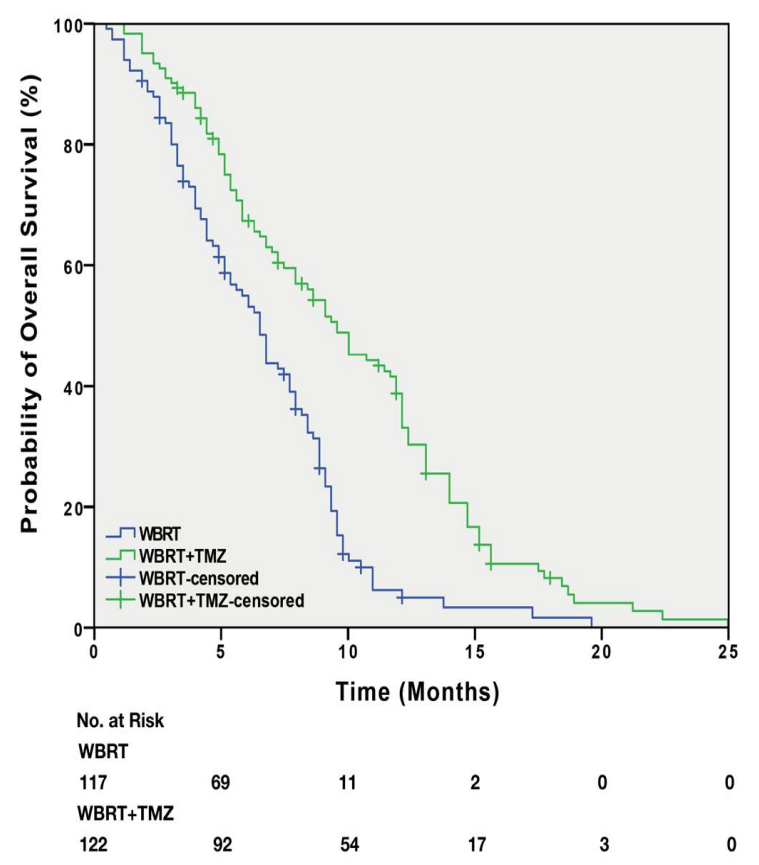

Figure 1: The overall survival of patients with brain metastases

Table 1: Baseline characteristics of BM subjects

\section{Neurocognition function (NCF) and QoL}

Table 3 shows deleterious changes over six months in line with Reliable Change Index threshold baseline. Prior to treatment, the scores for neurocognitive function and quality of life between the two groups were comparable $(p>$ 0.05 ). There were 24 out of 79 evaluated patients for WBRT-plus-TMZ group with deterioration in FACT. The proportion of patients with deterioration in FACT was significantly lower in WBRT-plus-TMZ group than in WBRT-alone group $(p<0.05)$.

\section{Adverse side effects}

All the patients were assessed for tolerability and adverse effects and the results are presented in Table 4. At baseline, the WBT + TMZ and WBTalone were comparable with respect to tolerability and adverse effects $(p<0.05)$. The predominant adverse effect was anemia (53.97 $\%)$, while, the most frequent non-hematologic adverse effect was asthenia (74.48 \%). Except for headaches, no other major difference was observed both treatment groups.

\section{DISCUSSION}

The strategies used in the management of BM from solid tumors have continued to evolve. Management of brain metastases typically requires a multidisciplinary approach.

\begin{tabular}{|c|c|c|c|c|c|c|c|}
\hline \multirow[b]{2}{*}{ Parameter } & \multicolumn{2}{|c|}{ WBT+TMZ (\%) } & \multicolumn{2}{|l|}{ WBT (\%) } & \multicolumn{2}{|l|}{ Total } & \multirow{2}{*}{$\underset{\text { value }}{P-}$} \\
\hline & $\begin{array}{c}\text { No. of Patients } \\
\text { (122) }\end{array}$ & $\%$ & $\begin{array}{c}\text { No. of Patients } \\
\text { (122) }\end{array}$ & $\%$ & $\begin{array}{c}\text { No. of Patients } \\
\text { (122) }\end{array}$ & $\%$ & \\
\hline \multicolumn{8}{|l|}{ AGE } \\
\hline$>60$ & 68 & 55.74 & 66 & 56.41 & 134 & 56.07 & 0.92 \\
\hline$\leq 60$ & 54 & 44.26 & 51 & 43.59 & 105 & 43.93 & \\
\hline \multicolumn{8}{|l|}{ Gender } \\
\hline Male & 68 & 55.74 & 68 & 58.12 & 136 & 56.9 & 0.71 \\
\hline Female & 54 & 44.26 & 49 & 41.88 & 103 & 43.1 & \\
\hline \multicolumn{8}{|l|}{ KPS } \\
\hline$\geq 70$ & 31 & 25.41 & 32 & 27.35 & 63 & 26.36 & 0.73 \\
\hline$<70$ & 91 & 74.59 & 85 & 72.65 & 176 & 73.46 & \\
\hline \multicolumn{8}{|l|}{ No. of BM } \\
\hline$>2$ & 23 & 18.85 & 23 & 19.66 & 46 & 19.25 & 0.88 \\
\hline$\leq 2$ & 99 & 81.15 & 94 & 80.34 & 193 & 80.75 & \\
\hline \multicolumn{8}{|l|}{$\begin{array}{l}\text { Extracranial } \\
\text { metastases }\end{array}$} \\
\hline Yes & 33 & 27.05 & 35 & 29.91 & 68 & 28.45 & 0.62 \\
\hline No & 89 & 72.95 & 82 & 70.09 & 171 & 71.55 & \\
\hline \multicolumn{8}{|c|}{$\begin{array}{l}\text { Primary disease } \\
\text { control }\end{array}$} \\
\hline Yes & 9 & 7.38 & 11 & 9.4 & 20 & 8.37 & 0.57 \\
\hline No & 113 & 92.62 & 106 & 90.6 & 219 & 91.63 & \\
\hline
\end{tabular}


Table 2: Analysis of objective response rate in patients with brain metastases

\begin{tabular}{|c|c|c|c|c|c|c|c|c|c|c|c|c|}
\hline \multirow{2}{*}{ Group } & \multicolumn{10}{|c|}{ Parameter } & \multirow[b]{2}{*}{ Total } & \multirow{2}{*}{$P$-value } \\
\hline & $C R$ & $\%$ & $\begin{array}{l}P R \\
\end{array}$ & $\%$ & $S D$ & $\%$ & $P D$ & $\%$ & ORR & $\%$ & & \\
\hline WBRT+TMZ & 10 & 8.2 & 59 & 48.36 & 8 & 6.56 & 45 & 36.89 & 69 & 56.56 & 117 & 0.03 \\
\hline WBRT & 5 & 4.27 & 33 & 28.21 & 12 & 10.26 & 67 & 57.26 & 38 & 32.48 & 122 & \\
\hline Total & 15 & & 92 & & 20 & & 112 & & 107 & & 239 & \\
\hline
\end{tabular}

Table 3: Deterioration over time relative to baseline, based on Reliable Change Index

\begin{tabular}{cccccc}
\hline \multirow{2}{*}{ Deterioration status } & \multicolumn{2}{c}{ WBT+TMZ } & \multicolumn{2}{c}{ WBT } & \multirow{2}{*}{$\boldsymbol{P}$-value } \\
\cline { 2 - 5 } & Deterioration & No Deterioration & Deterioration & No Deterioration & \\
At 3 months & 14 & 89 & 17 & 74 & 0.33 \\
HVLT & 16 & 87 & 20 & 71 & 0.25 \\
FACT & & & & 35 & 0.79 \\
At 6 months & 26 & 53 & 19 & 28 & 0.04 \\
HVLT & 24 & 55 & 26 & & \\
FACT & &
\end{tabular}

Table 4: Deterioration status from baseline in each examination using reliable change index

\begin{tabular}{|c|c|c|c|c|c|}
\hline \multirow{2}{*}{ Adverse event } & \multicolumn{2}{|c|}{ WBRT+TMZ ( $\mathrm{N}=122)$} & \multicolumn{2}{|c|}{ WBRT (N=117) } & \multirow[t]{2}{*}{$P$-value } \\
\hline & Grade I/II & Grade III/IV & Grade I/II & Grade III/IV & \\
\hline \multicolumn{6}{|l|}{ Hematologic } \\
\hline Lymphopenia & 43 & 2 & 38 & 1 & 0.64 \\
\hline Neutropenia & 51 & 11 & 38 & 6 & 0.57 \\
\hline Anemia & 71 & 4 & 53 & 1 & 0.31 \\
\hline Thrombopenia & 58 & 4 & 44 & 0 & 0.23 \\
\hline \multicolumn{6}{|l|}{ Non-hematologic } \\
\hline Asthenia & 65 & 23 & 71 & 19 & 0.43 \\
\hline Nausea & 64 & 25 & 60 & 17 & 0.37 \\
\hline Vomiting & 56 & 9 & 50 & 8 & 0.99 \\
\hline Headaches & 44 & 8 & 44 & 2 & 0.07 \\
\hline
\end{tabular}

In the present study, the effectiveness of combination of TMZ and WBT on neurocognition and QoL in the treatment of different kinds of solid tumors with BM was investigated. The intracranial ORR of BM given WBT + TMZ was significantly higher than that of the WBT alone. These results are in agreement with those obtained in previous studies, where it was speculated that WBT + TMZ may enhance ORR $[9,16]$. The median OS in WBT-plus-TMZ group, and WBT group appear better than those reported in previous studies [10]. This improvement may be due to fact that there were more patients in RPA classes I and II in the present study. Considerable improvement in quality of life was also observed. These results suggest that WBT + TMZ can prevent the degenerations in neurocognitive function and quality of life within six months, and that TMZ may prevent tumor recurrence in the brain.

The higher incidence of adverse side effects in the WBRT + TMZ group is in agreement with previous reports. However, the observed variations in incidents of adverse events between WBT + TMZ, and WBR- alone groups was not statistically significant.

\section{CONCLUSION}

The use of whole brain radiotherapy plus concomitant TMZ to treat patients with brain metastases can improve their intracranial ORR and median OS better than the use of WBRT alone. Incorporation of TMZ to whole brain radiotherapy provides a significant and clinically important survival benefits. Although the side effects are increased following TMZ addition, the toxicities are tolerable and manageable. Thus, the concomitant administration of $\mathrm{TMZ}$ and whole brain radiotherapy may improve efficacy in patients with brain metastasis.

\section{DECLARATIONS}

\section{Acknowledgements}

This study was supported by grants from the Natural Science Funds of China (No. 81171179), Fund for Key Natural Science Foundation of Guangdong (No. 2016B030230004), and the Educational Commission of Guangdong (No.2013CXZDA008), Key Projects of Health Collaborative Innovation of Guangzhou (No. 201400000003-2) to Prof. Xiaodan Jiang. Also by 
Part of the fund from The Guangdong Provincial Clinical Medical Centre for Neurosurgery (No. 2013B020400005).

\section{Conflict of Interest}

No conflict of interest associated with this work.

\section{Contribution of Authors}

We declare that this work was done by the authors named in this article and all liabilities pertaining to claims relating to the content of this article will be borne by them. Xiaodan Jiang conceived and designed the study and revised the manuscript. Yufei Zhan performed the experiments, collected and analysed the data, wrote the manuscript. All authors read and approved the final manuscript.

\section{REFERENCES}

1. Zimm S, Wampler GL, Stablein D, Hazra T, Young HF. Intracerebral metastases in solid-tumor patients: natural history and results of treatment. Cancer 1981; 48(2): 384-394.

2. Cappuzzo F, Mazzoni F, Maestri A, Di Stefano A, Calandri $C$, Crino L. Medical treatment of brain metastases from solid tumours. Forum (Genova) 2000; 10(2): 137-148.

3. Nussbaum ES, Djalilian HR, Cho KH, Hall WA. Brain metastases: Histology, multiplicity, surgery, and survival. Cancer 1996; 78(8): 1781-1788.

4. Suh JH, Chao ST, Vogelbaum MA. Management of brain metastases. Curr Neurol Neurosci Rep 2009; 9(3): 223230.

5. Brastianos HC, Cahill DP, Brastianos PK. Systemic therapy of brain metastases. Curr. Neurol Neurosci Rep 2015; 15(2): 518.

6. Bower M, Newlands ES, Bleehen NM, Brada M, Begent RJ, Calvert H, Colquhoun I, Lewis P. Multicentre CRC phase II trial of temozolomide in recurrent or progressive high-grade glioma. Cancer Chemother Pharmacol 1997; 40(6): 484-488.

7. Antonadou D, Paraskevaidis $M$, Sarris G, Coliarakis $N$, Economou I, Karageorgis P, Throuvalas N. Phase II Randomized Trial of Temozolomide and Concurrent Radiotherapy in Patients with Brain Metastases. J Clin Oncol 2002; 20(17): 3644-3650.

8. Verger E, Gil M, Yaya R, Vinolas N, Villa S, Pujol T, Quinto L, Graus F. Temozolomide and concomitant whole brain radiotherapy in patients with brain metastases: a phase II randomized trial. Int J Radiat Oncols Biol Phys 2005; 61(1): 185-191.

9. Addeo R, Caraglia M, Faiola V, Capasso E, Vincenzi B, Montella L, Guarrasi $R$, Caserta L, Del Prete $S$.
Concomitant treatment of brain metastasis with Whole Brain Radiotherapy [WBRT] and Temozolomide [TMZ] is active and improves Quality of Life. BMC Cancer 2007; 7: 18.

10. Gamboa-Vignolle C, Ferrari-Carballo T, Arrieta O, Mohar A. Whole-brain irradiation with concomitant daily fixeddose Temozolomide for brain metastases treatment: $A$ randomised phase II trial. Radiother Oncol 2012; 102(2): 187-191.

11. Stupp R, Mason WP, van den Bent MJ, Weller M, Fisher B, Taphoorn MJ, Belanger K, Brandes AA, Marosi C, Bogdahn $U$, et al. Radiotherapy plus concomitant and adjuvant temozolomide for glioblastoma. $N$ Engl J Med 2005; 352(10): 987-996.

12. Stupp R, Hegi ME, Mason WP, van den Bent MJ, Taphoorn MJB, Janzer RC, Ludwin SK. Effects of radiotherapy with concomitant and adjuvant temozolomide versus radiotherapy alone on survival in glioblastoma in a randomised phase III study: 5-year analysis of the EORTC-NCIC trial. The Lancet Oncol 2009; 10(5): 459-466.

13. Addeo R, De Rosa C, Vincenzo F, Luigi L, Gregorio C, Liliana M, Rosario G, Bruno V, Michele C, Salvatore DP. Phase 2 Trial of Temozolomide Using Protracted Lowdose and Whole-brain Radiotherapy for Nonsmall Cell Lung Cancer and Breast. Cancer Patients With Brain Metastases 2008; 113: 2524-2531.

14. Siena S. Dose-dense temozolomide regimen for the treatment of brain metastases from melanoma, breast cancer, or lung cancer not amenable to surgery or radiosurgery: a multicenter phase II study. Ann Oncol 2010; 21(3): 655-661.

15. Antonadou D, Coliarakis N, Paraskevaidis M, Athanasiou $H$, Sarris G, Synodinou M, Georgakopoulos G, Beroukas C, Karageorgis $P$, Throuvalas N. O-67 A multi-institutional trial comparing survival of patients with brain metastases from lung cancer treated with temozolomide plus radiotherapy versus to radiotherapy alone. Lung Cancer 2003; 41 Suppl 2: S234

16. Xia $D$, Zhen Z, Lin BC, Su HF, Chen HB, Fei SR, Fei ZH, Zhao $L H$, Jin XC, Xie CY. The efficacy and roles of combining temozolomide with whole brain radiotherapy in protection neurocognitive function and improvement quality of life of non-small-cell lung cancer patients with brain metastases. BMC Cancer 2017; 17: 42.

17. World Health Organization. Declaration of Helsinki. Br Med J 1996; 313(7070): 1448-1449.

18. Benedict RHB, Schretlen D, Groninger L, Brandt J. Hopkins Verbal Learning Test - Revised: Normative Data and Analysis of Inter-Form and Test-Retest Reliability. The Clin Neuropsychol 1998; 12(1): 43-55.

19. Cella DF, Tulsky DS, Gray G, Sarafian B, Linn E, Bonomi $A$, Silberman M, Yellen SB, Winicour $P$, Brannon J, et al. The Functional Assessment of Cancer Therapy scale: Development and Validation of the General Measure. $J$ Clin Oncol 1993; 11(3): 570-579. 